\title{
A COORDENAÇÃO PEDAGÓGICA E SUA IMPORTÂNCIA NO PROCESSO EDUCACIONAL: um estudo de caso no município de Uruguaiana-RS
}

\author{
Silvia Esther Azambuja Pereira ${ }^{1}$ \\ Julio Cesar Bresolin Marinho² \\ Edward Frederico Castro Pessano 3
}

\section{RESUMO}

A presente investigação trata-se de um trabalho qualitativo exploratório que busca identificar o perfil dos Professores Coordenadores Pedagógicos da Rede Municipal de Ensino no município de Uruguaiana/RS. Inicialmente foi aplicado um questionário no qual foi possível traçar as características dos investigados, diagnosticando suas dificuldades no desenvolvimento das suas práticas diárias e sobre o processo de reflexão crítica em relação aos múltiplos papéis assumidos por estes nas escolas da Rede Municipal. Através desse instrumento de pesquisa, também foi possível verificar a importância das reuniões de formação continuada promovidas pela Secretaria Municipal de Educação - SEMED no auxílio aos Professores Coordenadores Pedagógicos no desenvolvimento de suas funções. Os resultados indicaram que os Professores Coordenadores Pedagógicos possuem a percepção da sua importância dentro do sistema educacional da escola, atuando como mediadores do processo pedagógico e no auxílio aos professores. Segundo os dados encontrados, os investigados acreditam que as reuniões de formação continuada são fundamentais para as suas atuações nas instituições escolares e que a troca de experiência e informações entre seus pares, colabora para a qualificação de suas práticas. Os resultados encontrados corroboram com outros autores, salientando que o papel dos Professores Coordenadores Pedagógicos é imprescindível dentro da construção pedagógica nos estabelecimentos de ensino.

Palavras-chave: Coordenadores Pedagógicos. Ensino Fundamental. Perfil.

\footnotetext{
1 Especialista em Gestão Escolar pela Universidade do Norte do Paraná. Professora Coordenadora Pedagógica na Rede Municipal de Ensino do município de Uruguaiana/RS. Email: silviaestherazambujapereira@gmail.com

2 Mestre e Doutorando em Educação em Ciências pelo Programa de Pós-Graduação em Educação em Ciências da Universidade Federal do Rio Grande - FURG. Professor do Curso de Ciências da Natureza - Licenciatura da Universidade Federal do Pampa - Campus Uruguaiana. E-mail: juliomarinho@unipampa.edu.br

${ }^{3}$ Mestre e Doutor em Educação em Ciências - UFSM. Professor da Universidade Federal do Pampa. E-mail: edwpessano@gmail.com
} 


\title{
PEDAGOGICAL COORDINATION AND ITS IMPORTANCE IN THE EDUCATIONAL PROCESS: a case study in the city of Uruguaiana-RS
}

\begin{abstract}
The present investigation is an exploratory qualitative research which aims at identifying the profile of pedagogic coordinator teachers from the municipal schools situated in Uruguaiana/RS. Initially, it was applied a questionnaire where it was possible to trace the characteristics of the investigated people, diagnosing their difficulties in the development of their daily practices and about the critical reflexion process in relation to the multiple roles played by the interviewed in municipal system schools. Through this research tool, it was also possible to verify the importance of the continuing development meetings promoted by the Municipal Education Department, SEMED, helping pedagogic coordinator teachers in the development of their functions. The results indicated that the pedagogic coordinator teachers have the perception of their importance in the school educational system, acting as mediators of the educational process and helping teachers. According to the found data, the investigated subjects believe that the continuing development meetings are fundamental to their performances in the schools and that the exchange of experience and information among their pairs contribute to the qualification of their practices. The results corroborate with other authors, stressing that the role of pedagogic coordinator teachers is indispensable in the pedagogic construction in educational institutions.
\end{abstract}

Keywords: Pedagogic Coordinators. Elementary School. Profile.

\section{LA COORDINACIÓN PEDAGÓGICA Y SU IMPORTANCIA EN EL PROCESO EDUCATIVO: un estudio de caso en la ciudad de Uruguayana -RS}

\section{RESUMEN}

La presente investigación se trata de un trabajo cualitativo exploratorio que busca identificar el perfil de los Profesores Coordinadores Pedagógicos de la Red Municipal de Enseñanza en el municipio de Uruguayana/ RS. Inicialmente se aplicó un cuestionario donde fue posible trazar las características de los investigados, diagnosticando sus dificultades en el desarrollo de sus prácticas diarias y sobre el proceso de reflexión crítica en relación a los múltiples roles asumidos por éstos en las escuelas de la Red Municipal. A través de ese instrumento de investigación, también fue posible verificar la importancia de las reuniones de formación continuada promovidas por la Secretaría Municipal de Educación, SEMED, en el auxilio a los Profesores Coordinadores Pedagógicos en el desarrollo de sus funciones. Los resultados indicaron que los profesores coordinadores pedagógicos poseen la percepción de su importancia dentro del sistema educativo de la escuela, actuando como mediadores del proceso pedagógico y en el auxilio a los profesores. Según los datos encontrados, los investigadores creen que las reuniones de formación continua son fundamentales para sus actuaciones en las instituciones escolares y que el intercambio de experiencia e información entre sus pares, colabora para la calificación de sus prácticas. Los resultados encontrados 
corroboran junto con los de otros autores, subrayando que el papel de los Profesores Coordinadores Pedagógicos son imprescindibles dentro de la construcción pedagógica en los establecimientos de enseñanza.

Palabras clave: Coordinadores Pedagógicos. Enseñanza fundamental. Perfil.

\section{INTRODUÇÃO}

O dicionário Larousse Cultural (1992) define a palavra coordenar como consistindo em "dispor em certa ordem, segundo determinado sistema, organizar, arranjar". Essas significações possibilitam-nos, entre outros aspectos, a também refletir sobre a função do Coordenador Pedagógico dentro das instituições escolares. Em nosso compreender esse profissional da educação é aquele que organiza, orienta e harmoniza o trabalho do corpo docente, visando à efetivação do Projeto Político-Pedagógico, atuando como um catalisador entre os processos e as pessoas.

Considerando ainda que quem gerencia a prática pedagógica de sala de aula é o professor, o Coordenador Pedagógico, segundo Vasconcellos (2006, p. 89) tem as seguintes atribuições dentro das instituições educacionais:

- Acolher o professor em sua realidade, em suas angústias;

- Fazer a crítica dos acontecimentos, ajudando a compreender a própria participação do professor no problema, a perceber as suas contradições (e não acobertá-las);

- Trabalhar em cima da ideia de processo de transformação;

- Buscar caminhos alternativos; fornecer materiais; provocar para o avanço;

- Acompanhar a caminhada no seu conjunto, nas suas várias dimensões.

Nesse sentido, o presente trabalho busca a partir de um diagnóstico, entender melhor a atuação dos Coordenadores Pedagógicos no município de Uruguaiana/RS.

A Rede Municipal de Ensino de Uruguaiana/RS possui um total de 16 escolas de Ensino Fundamental, sendo 10 classificadas como urbanas e 6 escolas classificadas como rurais. A Rede conta atualmente, com 37 
profissionais que atuam como Coordenadores Pedagógicos, desenvolvendo suas funções junto a 657 professores do Ensino Fundamental e aproximadamente 12.700 estudantes do $1^{\circ}$ ao $9^{\circ}$ ano, segundo as informações da Secretaria Municipal de Educação - SEMED.

Tendo em vista os preceitos e aspectos citados anteriormente, o presente trabalho refere-se à questão da coordenação do trabalho pedagógico realizado dentro das escolas da Rede Municipal de Ensino, a qual é executada efetivamente pelos profissionais denominados "Professores Coordenadores Pedagógicos". Esses profissionais estão em constante busca pela sua identidade profissional e sendo assim, alguns autores como Celso Vasconcellos (2006) e Paulo Freire $(1982 ; 2000)$ foram fundamentais para embasar esse estudo.

Neste cenário e para melhor conhecer a realidade desses profissionais, fez-se necessário investigar $\circ$ perfil dos Professores Coordenadores Pedagógicos, analisando quais são as suas principais atribuições e quais são as maiores dificuldades e limitações encontradas no desenvolvimento de seu trabalho de Professor Coordenador Pedagógico na Rede Municipal de Ensino de Uruguaiana/RS.

O interesse pelo tema surgiu a partir da atuação da autora principal deste trabalho na Rede Municipal de Ensino, a qual desempenhou a função de Professora Coordenadora Pedagógica até o ano de 2016 em uma escola do meio rural. A pesquisadora é também licenciada em Matemática e Especialista em Gestão Escolar e começou a observar, durante as reuniões mensais de formação continuada promovida pela SEMED, que muitos de seus pares não possuíam a clareza de quais eram suas atribuições dentro das escolas. Ainda, sentiam dificuldades em realizar o seu trabalho por não terem a habilitação específica em Supervisão Escolar ou Gestão Escolar. Desta forma e contribuindo com nosso estudo, recorremos a Vasconcellos (2006, p. 85), o qual nos traz a seguinte reflexão:

Afinal de contas, qual o papel da supervisão? Diversas são as reclamações que emergem do cotidiano dos coordenadores: sentem-se sozinhos, lutando em muitas frentes, tendo que 
desempenhar várias funções. Qual seria sua efetiva identidade profissional? A sensação que têm, com frequência, é de que são "bombeiros" a apagar os diferentes focos de "incêndio" na escola, e no final do dia vem o amargo sabor de que não se fez nada de muito relevante... Sentem ainda o distanciamento em relação aos professores, a desconfiança, a competição, a disputa de influência e de poder, etc.

A partir da análise das atribuições previstas em Plano de Carreira, verificou-se a dimensão do trabalho do Professor Coordenador Pedagógico nas escolas da Rede Municipal de Ensino e percebeu-se que esta pesquisa vem ao encontro das reais necessidades da demanda escolar e que possui a capacidade de contribuir para com as diferentes realidades que ocorrem dentro dos espaços educacionais. Portanto e partindo de tais necessidades, este estudo teve como finalidade geral determinar o perfil dos Professores Coordenadores Pedagógicos que atuam na Rede Municipal de Ensino de Uruguaiana/RS e contribuir com futuras investigações sobre o tema.

\section{METODOLOGIA}

A presente pesquisa trata-se de uma abordagem qualitativa e exploratória, pois busca "levantar informações sobre um determinado objeto, delimitando assim um campo de trabalho, mapeando as condições de manifestação desse objeto" (SEVERINO, 2007, p. 123).

Os caminhos metodológicos escolhidos para o desenvolvimento da pesquisa residiram, inicialmente, na aplicação de questionário semiestruturado aos Professores Coordenadores Pedagógicos do Ensino Fundamental.

Os referidos questionários foram fundamentais para a coleta dos dados e foram aplicados no segundo semestre de 2015, durante uma reunião de formação continuada, na SEMED, na qual estavam presentes 20 Coordenadores Pedagógicos.

Além da realização dos questionários, realizamos o acompanhamento de cinco reuniões de formação continuada dos Professores Coordenadores Pedagógicos, promovidas pela SEMED. Para O acompanhamento das reuniões, elaboramos planilhas específicas para cada uma, registrando a 
data e pauta da reunião, bem como observações relevantes na visão dos pesquisadores.

O método de análise dos dados coletados se deu através da Análise de Conteúdo (BARDIN, 1977). Para tanto, trabalhamos com duas categorias a priori: perfil dos Professores Coordenadores Pedagógicos e atuação profissional dos Professores Coordenadores Pedagógicos.

Também utilizamos o cálculo de percentual simples para trabalho com os dados numéricos com a finalidade de comparar os resultados encontrados e proporcionar uma melhor visualização dos dados.

Por fim, foi ainda utilizada a técnica da nuvem de palavras (SILVA, 2013), pois os Coordenadores Pedagógicos sugeriram nos questionários, diferentes temas para as reuniões de formação continuada e para uma melhor visualização das ideias coletivas, suas respostas foram apresentadas e analisadas pela técnica citada anteriormente, a qual possibilidade uma representação gráfica dos dados encontrados.

\section{RESULTADOS E DISCUSSÃO}

\subsection{O perfil dos professores coordenadores pedagógicos do município de Uruguaiana/RS}

A partir dos dados coletados na pesquisa, foi possível verificar que os Professores Coordenadores que atuam na Rede Municipal de Ensino do município de Uruguaiana/RS são a grande maioria, mulheres que possuem de 31 a 40 anos de idade, conforme mostra a figura 1:

FIGURA 1- Idade e Sexo dos Professores Coordenadores Pedagógicos

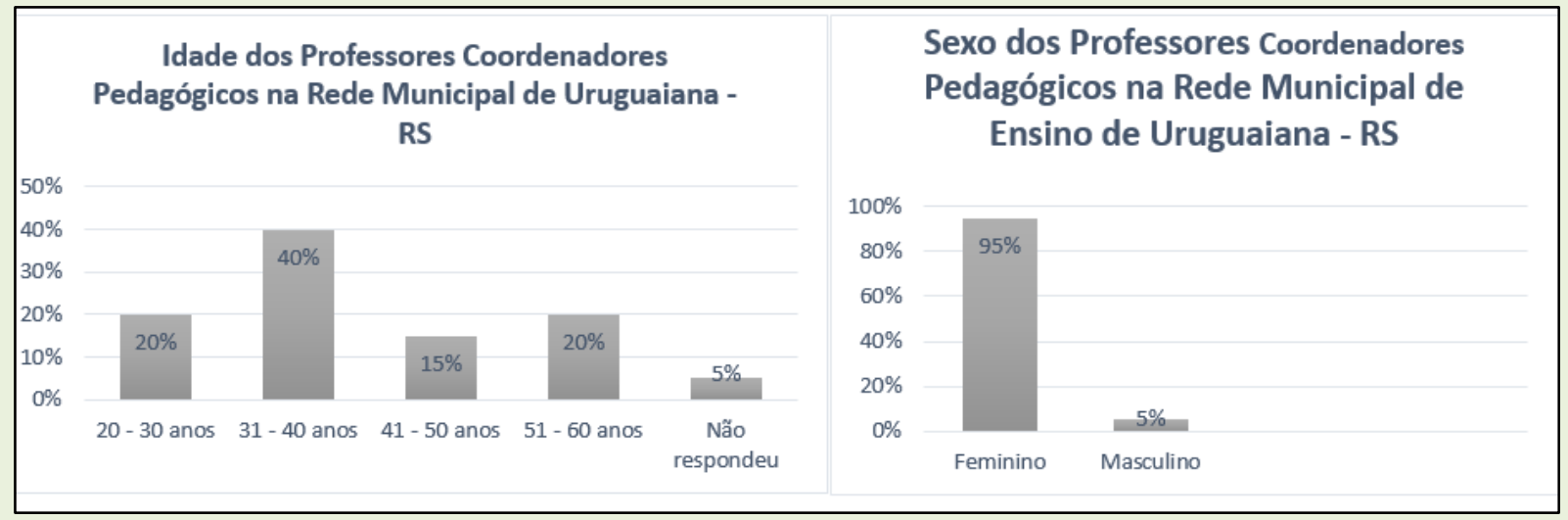

Fonte: Dados da pesquisa. 
A partir da criação da Lei de Diretrizes e Bases da Educação Nacional, 9394/96, foi definida a forma de ingresso dos "especialistas em educação" em sua área de atuação:

A formação de profissionais de educação para administração, planejamento, inspeção, supervisão e orientação educacional para a educação básica, será feita em cursos de graduação em pedagogia ou em nível de pós-graduação, a critério da instituição de ensino, garantida, nesta formação, a base comum nacional (BRASIL, 1996, Art. 64).

Porém, a partir do Concurso Público ocorrido no ano de 2011, para ingresso no quadro do Magistério, a Secretaria Municipal de Educação de Uruguaiana/RS, SEMED, autorizou-se que docentes habilitados em qualquer Licenciatura Plena, prestassem as provas de Concurso Público para ingressarem na Rede Municipal como Professores Coordenadores Pedagógicos.

Desta forma, a grande maioria desses profissionais não possui habilitação específica em Supervisão Escolar, conforme aponta a figura 2, fator que pode estar contribuindo para com os conflitos de identidade existente no grupo destes profissionais, conforme já citado anteriormente.

FIGURA 2- Formação dos Professores Coordenadores Pedagógicos

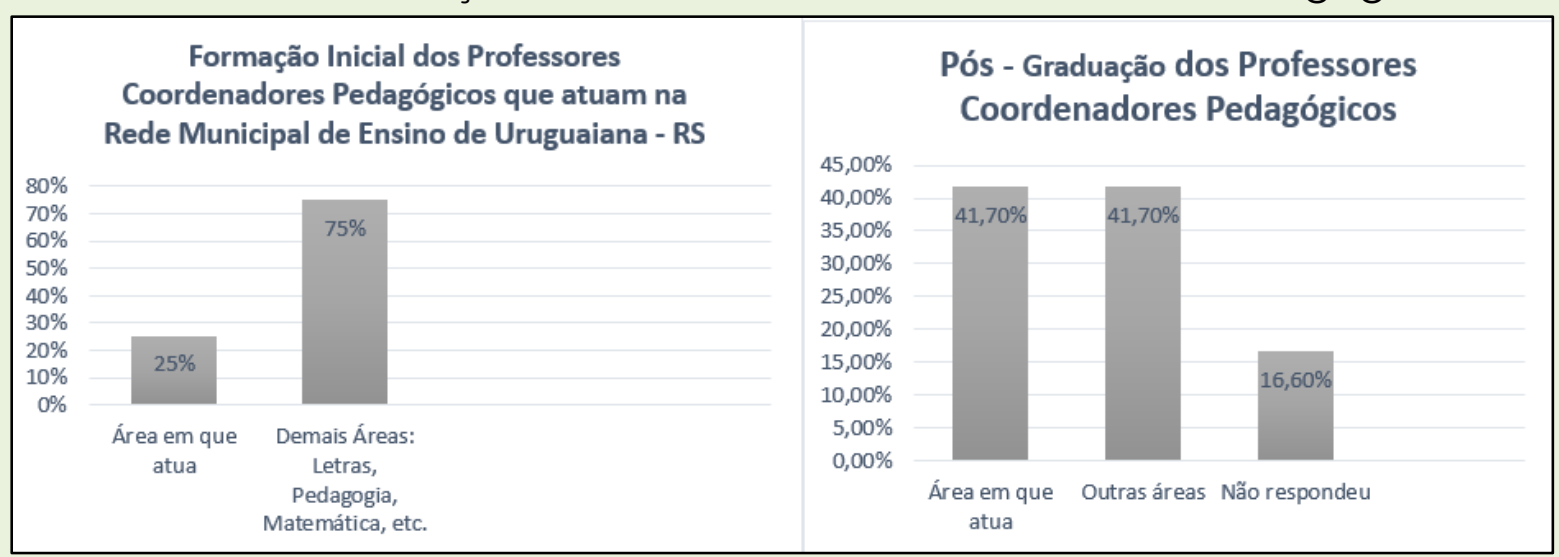

Fonte: Dados da pesquisa.

Esses profissionais que estão à frente da gestão pedagógica das escolas da rede pública municipal possuem em $75 \%$ dos casos, habilitação em outras áreas de formação como: Letras, Pedagogia, Matemática, 
História, Educação Física, entre outras. Porém, apenas $42 \%$ dos Coordenadores Pedagógicos que responderam à pesquisa, procuraram realizar Curso de Especialização na área em que estão atuando, conforme mostra a fala do Coordenador Pedagógico A:

"Antes de eu ter a formação em Supervisão e a pouca experiência na área sentia dificuldades com relação a diversas coisas do próprio cotidiano. Hoje, com a formação e um pouco mais de experiência já compreendo e consigo empregar no meu trabalho diário".

Segundo o PNE, Plano Nacional de Educação, a qualificação do pessoal docente se apresenta como um dos maiores desafios da educação brasileira. Assim, ressaltamos que a melhoria da qualidade do ensino, indispensável para assegurar à população brasileira o acesso pleno à cidadania e à inserção nas atividades produtivas, constitui um compromisso da nação e depende muito da qualificação/formação contínua dos docentes.

Nesse sentido citamos a Meta 16 do PNE a qual propõe o seguinte sobre a formação:

em nível de pós-graduação, 50\% (cinquenta por cento) dos professores da educação básica, até o último ano de vigência deste PNE, e garantir a todos(as) os(as) profissionais da educação básica formação continuada em sua área de atuação, considerando as necessidades, demandas e contextualizações dos sistemas de ensino (BRASIL, 2014).

As próximas imagens (Figura 3) mostram o tempo de atuação dos Professores Coordenadores Pedagógicos no Magistério e também o tempo de atuação desses profissionais como Professores Coordenadores Pedagógicos na Rede Municipal de Ensino. 
FIGURA 3 - Tempo de Atuação dos Professores Coordenadores Pedagógicos

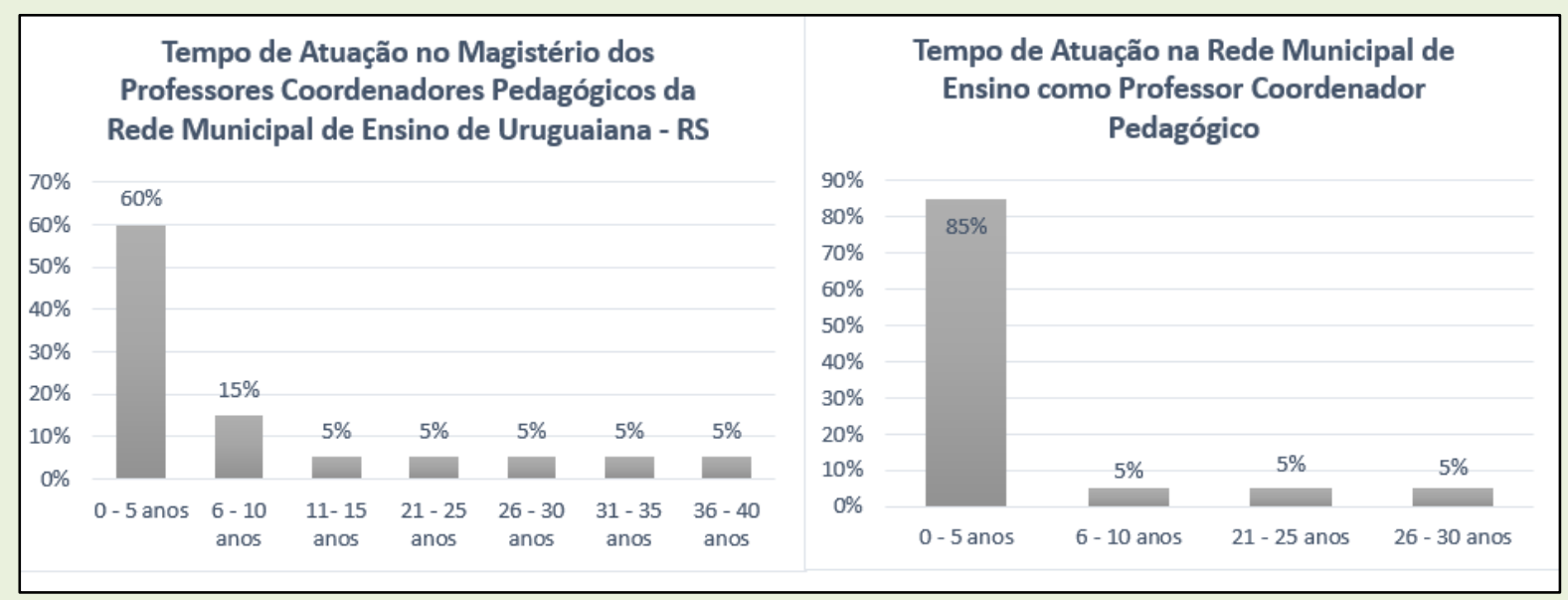

Fonte: Dados da pesquisa.

De acordo com os dados obtidos e apresentados na figura 3, é possível constatar que $60 \%$ dos Professores Coordenadores Pedagógicos possuem de 0 a 5 anos de atuação no magistério, sendo que $85 \%$ estão atuando na função de Professores Coordenadores Pedagógicos de 0 a 5 anos. Os referidos dados evidenciam que estes profissionais ingressaram na carreira a partir de 2011 na rede municipal de ensino, quando a formação profissional foi modificada nos editais de concursos.

Portanto é possível traçar o perfil desses profissionais, os quais em grande maioria são mulheres, de 31 a 40 anos de idade, que possuem formação inicial em áreas diferentes de sua área de atuação e estão exercendo a função há pouco tempo.

\subsection{Atuação profissional dos professores coordenadores pedagógicos do município de Uruguaiana/RS}

Para uma melhor identificação do perfil destes profissionais, os Professores Coordenadores Pedagógicos foram questionados sobre as suas atribuições e atividades durante o desenvolvimento dos seus cargos, sendo que 53\% respondeu que entre as atividades (Tabela 1), a principal é atuar como um mediador do processo pedagógico, no qual se enquadram questões como o monitoramento da disciplina dos estudantes. Isso demosntra que pode estar ocorrendo um subaproveitamento destes 
profissionais e consequentemente uma perda das suas contribuições para com as atividades fins de ensino.

TABELA 1 - Do seu ponto de vista, qual é a sua maior atribuição enquanto Coordenador Pedagógico?

\begin{tabular}{|c|c|}
\hline Respostas & Percentual \\
\hline $\begin{array}{l}\text { Atuar como um mediador do processo pedagógico } \\
\text { Auxílio às atividades dos professores } \\
\text { Outros } \\
\text { Coordenar o grupo de docentes }\end{array}$ & $\begin{array}{l}53 \% \\
35 \% \\
8 \% \\
4 \%\end{array}$ \\
\hline Total & $100 \%$ \\
\hline
\end{tabular}

Fonte: Dados da pesquisa.

A partir das respostas obtidas, foi possível verificar que os Professores Coordenadores Pedagógicos possuem consciência da importância de sua função dentro das escolas e da sua atuação em conjunto com o corpo docente, conforme verificado a partir da fala do Professor Coordenador Pedagógico B:

"Atuar dentro da escola buscando refletir com os docentes em relação à prática pedagógica e os resultados atingidos pela mesma, sempre atuando de maneira conjunta com o grupo de professores para criar estratégias para melhorar o processo de ensino aprendizagem".

Sabemos que a esfera de atuação do Professor Coordenador Pedagógico é bastante ampla e inclui diferentes questões referentes ao currículo, ensino e aprendizagem, disciplina, avaliação da aprendizagem, recursos entre outros.

Esse papel dentro dos processos de ensino é também reconhecido e manifestado na literatura em que, por exemplo, Medina (1997, p. 99) salienta a importância do papel do Coordenador Pedagógico quando manifesta:

Tem uma contribuição específica e importante a dar no processo de ensinar e aprender: trabalhar com o professor na identificação das necessidades, das satisfações, das perguntas, das respostas possíveis e das inúmeras dúvidas que vão surgindo no fazer diário, atuando em conjunto com o regente de classe. Dessa maneira, supervisor e professor, cada um no lugar que ocupam dentro da escola, estariam simultaneamente, ora se assessorando no processo de ensinar, ora 
identificando as demandas (pedidos) da escola que emergem do agir e reagir diário com os alunos, pais e comunidade escolar.

Nesse sentido, Freire (1982, p. 95) afirma:

\begin{abstract}
A educação, não importando o grau em que se dá, é sempre uma teoria do conhecimento que se põe em prática [...] O supervisor é um educador e, se ele é um educador, ele não escapa na sua prática a esta natureza epistemológica da educação. Tem a ver com o conhecimento, com a teoria do conhecimento. O que se pode perguntar é: qual o objeto de conhecimento que interessa diretamente ao supervisor? Aí talvez a gente pudesse dizer: é o próprio ato de conhecimento que está se dando na relação educador/educando.
\end{abstract}

Pelos dados obtidos, bem como com as colocações dos autores já apresentados, compreendemos que supervisionar não é fiscalizar, mas sim, construir coletivamente, o que significa alcançar a participação de todos na caminhada da construção e da manutenção da proposta pedagógica da escola. Portanto supervisionar requer planejamento participativo, avaliação participativa, cooperação e um ambiente de trabalho aberto e democrático, baseado na coletividade e com suporte da gestão escolar.

Os Coordenadores Pedagógicos foram também questionados sobre as dificuldades encontradas ao desempenhar sua função (Tabela 2). Nesse questionamento, dados interessantes foram observados, nos quais, por exemplo, cerca de $35 \%$ dos Coordenadores Pedagógicos manifestam que os docentes pensam que estão nas escolas para "fiscalizar" o trabalho desenvolvido por estes. Essa questão é retratada através da fala do Professor Coordenador Pedagógico C:

"A falta de compreensão de alguns professores por achar que estamos fiscalizando seus trabalhos, mas na verdade estamos auxiliando para uma melhor qualidade no ensino aprendizagem".

TABELA 2 - Quais as dificuldades que encontras em sua prática diária como Coordenador Pedagógico na Rede Municipal de Ensino?

\begin{tabular}{lc}
\hline \multicolumn{1}{c}{ Respostas } & Percentual \\
\hline A falta de compreensão e apoio dos professores & $35 \%$ \\
A falta de recursos e/ou condições de trabalho & $30 \%$ \\
A grande demanda e as múltiplas funções & $15 \%$ \\
Aplicar a proposta pedagógica & $5 \%$ \\
A realidade externa da escola & $5 \%$
\end{tabular}

Revista Exitus, Santarém/PA, Vol. 8, № 3, p. 254 - 279, SET/DEZ 2018. 


\begin{tabular}{cc} 
A falta de experiência no cargo & $5 \%$ \\
Não possuem dificuldades & $5 \%$ \\
\hline Total & $100 \%$ \\
\hline
\end{tabular}

Fonte: Dados da pesquisa.

Para melhor discutirmos e refletirmos sobre os dados, buscamos a visão de Vasconcellos (2006, p. 91):

O supervisor não pode "queimar" a relação com os docentes. Toda relação humana autêntica se baseia na crença da possibilidade do outro, de que ninguém é melhor ou superior a ninguém. Acreditar que o outro pode mudar, que o que the faltou até então foi efetiva oportunidade ou percepção da necessidade. Este é o ponto de partida: confiar que o professor pode mudar sua visão e postura em relação à prática pedagógica. Precisamos nos trabalhar nesta direção, desarmar preconceitos, buscar sinceramente esta crença.

Esta proposta de ação da Coordenação Pedagógica como ação conjunta onde todos ensinam e todos aprendem - leva o especialista em educação a uma ação dinâmica, não só burocrática (porque a burocracia faz parte das atribuições do supervisor, mas não é predominante).

Sendo assim, a definição das funções e atribuições relativas a uma função, é tarefa essencial para estabelecer uma linha de ação em sua atuação profissional. Múltiplas são as funções do Coordenador Pedagógico e, na prática, elas formam um todo indissociável com perfeita interação entre elas.

A descriminação das funções e atribuições do supervisor é importante para o desempenho eficiente deste profissional, pois direciona o estilo de supervisão, ao mesmo tempo em que fornece o suporte teórico necessário ao exercício de qualquer profissão.

Cabe destacar então que a Lei 4.111 (URUGUAIANA, 2012), que estabelece $\bigcirc$ Plano de Carreira do Magistério Público Municipal de Uruguaiana que institui o respectivo Quadro de Cargos e Funções e dá outras providências, cita as atribuições do Professor Coordenador Pedagógico na Educação Infantil e no Ensino Fundamental:

a. coordenar a elaboração da Proposta Pedagógica da Escola;

b. elaborar o Plano de Ação da Coordenação Pedagógica, a partir da Proposta Pedagógica da Escola; 
c. assessorar e acompanhar as atividades para efetivação da Proposta Pedagógica quanto ao planejamento, docência e avaliação;

d. acompanhar o processo de ensino e de aprendizagem, tendo em vista a continuidade, avaliando e reavaliando as ações pedagógicas;

e. participar na tomada de decisões relativas à efetivação da Proposta Pedagógica e calendário escolar;

f. coordenar reuniões pedagógicas e os conselhos de classe;

g. analisar o histórico escolar dos alunos com vistas a adaptações, e ou regularização da vida escolar;

h. definir estratégias para inclusão de alunos com necessidades educacionais especiais;

i. participar na elaboração, execução e avaliação de projetos;

j. participar da definição de critérios para constituição das turmas e da organização do quadro de pessoal e da carga horária;

k. participar de reuniões técnico-administrativas e pedagógicas na Escola e da Secretaria Municipal de Educação;

I. integrar grupos de trabalho e comissões;

m. sistematizar os estudos de recuperação de alunos em conjunto com a direção, professores e orientador das relações humanas;

n. participar no processo de integração família-escola-comunidade escolar e local.

Podemos ver então, que as funções e atribuições preveem de forma adequada como deve ser o trabalho destes profissionais, contudo, as ações reais dentro dos espaços escolares muitas vezes não condizem com a perspectiva ideal.

Assim, citamos abaixo Alves e Garcia (1990, p. 30) os quais contribuem com essas reflexões, complementando sobre as atribuições dos Professores Coordenadores Pedagógicos:

Uma das funções específicas da Supervisão Escolar é a socialização do saber docente, na medida em que a ela cabe estimular a troca de experiências entre os professores, a discussão e a sistematização da prática pedagógica, que contribuirá para a construção não só de uma teoria mais compatível à realidade brasileira, mas também dos educadores coletivo.

A Coordenação Pedagógica se efetiva no grupo, num trabalho participativo com a comunidade escolar e desta forma, o trabalho do supervisor merece ser ressaltado, conforme salientado por Rangel (1997, p. 16):

Todos nós somos desafiados a pensar e a agir de modo mais amplo, no sentido da perspectiva social, e mais fundamentado, no sentido da consistência teórica dos atos. [...] O ensino é um ato educativo e, portanto, social, se o professor é um profissional da educação e, portanto, um agente sociopolítico, se o especialista é um professor e, 
portanto um educador, a nossa ação educacional estará intrinsecamente comprometida com as questões sociais.

Dentre as atribuições do Professor Coordenador Pedagógico, é necessário destacar questões sobre o currículo, a avaliação, a dinâmica de aulas, a elaboração de materiais e o suporte ao uso de diferentes metodologias de ensino, além de decisões sobre atividades extraclasse, decisões sobre estudos do meio, as análises de casos disciplinares, a promoção de ações interdisciplinares, o uso dos espaços multifuncionais da escola (laboratórios, informática, biblioteca, sala de vídeo), as discussões sobre projetos em desenvolvimento e a programação de datas comemorativas e eventos.

Mas é possível afirmar que não são apenas as atividades citadas anteriormente, especialmente pelo fato de que o coordenador pedagógico é um dos principais agentes de viabilização da proposta pedagógica da escola. Porém, em muitas ocasiões, seu papel é minimizado e ele é visto como um "preenchedor" de formulários e tabelas.

Segundo Vasconcellos (2006, p. 87), existe ainda uma definição negativa do papel do Coordenador Pedagógico. Segundo ele, o supervisor não é fiscal do professor, "quebra-galho", "tapa-buraco", burocrata ou de gabinete. Diz o autor, que na definição positiva do papel do supervisor, que a Coordenação Pedagógica é a articuladora do Projeto Político Pedagógico da escola, organizando a reflexão, a participação e os meios para a concretização do mesmo, de tal forma que a escola possa cumprir sua tarefa de propiciar que todos os alunos aprendam e se desenvolvam como seres humanos plenos.

Essa visão fica clara na fala do Coordenador Pedagógico D sobre suas atribuições na escola: "É acompanhar, analisar o trabalho desenvolvido na escola fazendo com que o PPP (Projeto Político Pedagógico) seja realmente aplicado no dia a dia buscando um ensino de qualidade. Trabalhar junto com o professor em equipe".

$\mathrm{Na}$ instituição em que o Coordenador está inserido, também é responsável pela sua gestão. Ao assumir a tarefa de Coordenação, o 
profissional deve estar preparado para não sucumbir à idealização e rejeição iniciais, ou mesmo no transcorrer do trabalho na instituição. Também deve estar preparado para o diagnóstico da instituição em que trabalha. Não cabe a ele apenas o planejamento, a orientação e o acompanhamento do trabalho pedagógico, mas, paralelamente a isso, a atividade diagnóstica, em seu sentido mais amplo, de análise da instituição. Para tanto, o Coordenador, ou qualquer gestor institucional, deve desenvolver uma capacidade de entendimento das relações interpessoais que extrapole o conhecimento específico sobre as dimensões política e cognitiva do processo educativo. É fundamental uma perspectiva de leitura da dimensão afetiva, de interpretação dos conflitos.

Dessa forma, poderá propor estratégias que, de um lado, sejam condizentes com a finalidade explícita da instituição e, de outro, levem em conta suas finalidades implícitas.

Os autores Placco e Almeida (2010, p. 142), colaboram com essa discussão e perspectiva através do seguinte texto:

Para desenvolver o seu trabalho de coordenação pedagógica, o coordenador precisa desvendar alguns pontos de estrangulamento presentes nas relações ali presentes. As combinações são infinitas, podendo ir de um único sujeito em relação à escola toda, como entre alunos, alunos e professores, entre equipe técnica e professores, inspetores e alunos, merendeiras e secretários, entre outros. Conhecer e fazer são atribuições centrais do professor coordenador.

A identificação e resolução de conflitos permite que o foco do trabalho possa ser direcionado adequadamente, evitando o fracasso certo de atividades muito bem planejadas, mas pouco pertinentes para determinados contextos. Por meio da mediação das relações de seu plano de trabalho, cabe ao Coordenador instrumentalizar o grupo para manejar os conflitos que se apresentem na instituição, favorecendo, assim, o processo de amadurecimento e a construção da autonomia.

Em síntese, o projeto de trabalho da Coordenação deve também ancorar-se nos sujeitos reais que, com suas demandas e dinâmicas pessoais, dão vida à instituição. 
Também é importante destacar a importância deste profissional em abrir espaços dentro da instituição para a formação continuada do grupo de professores, conforme a fala do Coordenador Pedagógico E:

\begin{abstract}
"Auxiliar, acompanhar o professor tanto no seu planejamento como em sua formação; promover estudos com o quadro docente sobre os principais problemas ou dilemas que ocorrem na escola, principalmente sobre a aprendizagem dos alunos e sobre os alunos com necessidades especiais e dar o suporte necessário no dia-a-dia escolar".
\end{abstract}

A função da Coordenação Pedagógica pode ser compreendida também, como um processo em que um professor, em princípio mais experiente e mais informado, orienta outro professor ou candidato a professor no seu desenvolvimento humano e profissional de maneira amigável e humana, não deixando com que a sua imagem seja de alguém onipotente e detentor do saber. Porém, como visto anteriormente, um percentual alto, em que 85\%, desses profissionais ingressaram a menos de 5 anos na função e 75\% não possuem habilitação específica na área.

Nessa perspectiva, questionamos se a falta de habilitação na área em que atuam, pode ser considerado um fator preponderante para possíveis insucessos ou prejuízos para com os processos educacionais. As respostas podem ser visualizadas conforme a tabela 3 abaixo.

TABELA 3 - Acreditas que a falta de habilitação em Coordenação Pedagógica ou Supervisão Escolar prejudica o teu desempenho na escola? $\operatorname{Sim}(35 \%)$, Não (55\%), Não respondeu (10\%)

\begin{tabular}{lc}
\hline \multicolumn{1}{c}{ Respostas } & Percentual \\
\hline Não, porque se aprende com a prática & $25 \%$ \\
Sim, porque para desempenhar a função é necessária & $25 \%$ \\
formação & $20 \%$ \\
Não, porque é possível se preparar de outras formas & $10 \%$ \\
Não, porque tenho habilitação & $10 \%$ \\
Sim, pois sem formação apresentei dificuldades & $10 \%$ \\
Não respondeu & $100 \%$ \\
\hline \multicolumn{2}{c}{ Total } \\
\hline
\end{tabular}

Fonte: Dados da pesquisa. 
Visto que, a função do Professor Coordenador Pedagógico se efetiva na prática e para que essa ação tenha êxito enquanto gestores da aprendizagem e corresponsáveis pela qualidade do ensino é imprescindível um aprendizado contínuo e a busca de novas estratégias e caminhos.

Assim sendo, para um número elevado desses profissionais, $25 \%$, se aprende a exercer a função na prática. Porém, 10\% dos Coordenadores Pedagógicos, ressaltam que sem a formação inicial, apresentaram dificuldade ao exercitar a função. Entretanto, renovação, inovação e formação constantes, com muita reflexão, tolerância, diálogo, parceria e participação coletiva, são itens fundamentais no exercício dessa função.

O Coordenador Pedagógico exerce um relevante papel na formação do professor e esta importância, deve-se à própria especificidade de sua função, que é planejar e acompanhar a execução de toda a Proposta Pedagógica da escola, já que ele é um articulador do processo de ensino e aprendizagem.

Então, seguindo esta linha de pensamento, assim como o professor não deve desistir do aluno, o supervisor não pode desistir do professor. Para que a proposta pedagógica da escola se efetive, é necessário que o coordenador pedagógico realize intervenções. A sua atuação pode ocorrer de maneira diversificada, seja no atendimento individualizado ao professor; orientação individual ou coletiva para o planejamento de sala de aula; coordenação das reuniões pedagógicas; busca de subsídios para os docentes; análise de material didático; estímulo à pesquisa e avaliação da aprendizagem dos alunos.

Para ilustrar a importância das responsabilidades dos Professores Coordenadores Pedagógicos como gestores e articuladores desse processo, Freire (2000, p. 57) nos lembra:

A gente acha que a formação do professor vai se dar em um mês, um, dois ou quatro anos. Não existe formação que termina. A formação do professor é contínua, permanente. Porque nesse processo de educar não existe tempo. E toda e qualquer inquietação individual deve ser coletivizada. Essas duas coisas andam juntas. Sempre. Não é possível separar o indivíduo do grupo. 
Portanto, não existe aquela coisa de eu ditar - ou alguma pessoa do grupo ditar - alguma necessidade. Ele tem de sugerir a ser coletivizada, pois não existe indivíduo sem grupo. Nem grupo sem indivíduo. O saber é construído junto. E aí ele espalha o que eu sei o que eu não sei. Ele me retrata, retrata você. E isso é difícil. Porque viver em grupo não é fácil. Mas eu acho que o ato de educar se dá nele. Fora dele, não há educação.

Os momentos de atuação do Coordenador Pedagógico como agente de formação continuada do professor, são aqueles em que ele se reúne com o conjunto de docentes para discutir questões e problemas pedagógicos, isto é, referentes à sala de aula, ao conteúdo de ensino, ao desempenho dos educandos e ao relacionamento com os alunos.

Nessa condição, ele assume um papel de mediador, de orientador do grupo. É fundamental também que o Coordenador Pedagógico concretize também as suas ações no acompanhamento das atividades dos professores em sala de aula, pois isto Ihe dá um suporte e embasamento para discutir e analisar os problemas decorrentes desse contexto, em uma perspectiva diferenciada e abrangente. Nas reuniões pedagógicas é preciso ter a prática da sala de aula como referência e fazer uma reflexão sobre ela. Segundo Vasconcellos (2006, p. 125):

Ter a prática como objeto, contudo, não pode significar uma "feira" de relatos de experiências, onde um fala, outro fala, mas não há confronto das práticas, entre si e com o referencial da escola, nada é sistematizado. A prática pela prática não nos leva muito longe. É preciso que seja atravessada pela visão crítica. O processo de mudança da realidade exige a prática (o que muda a realidade é a ação), bem como a reflexão sobre ela (uma vez que não é qualquer ação que produz a mudança que desejamos).

A Coordenação Pedagógica, centrada nos processos educacionais e na formação dos professores, indica um redirecionamento do trabalho dos agentes, voltando à atenção para os problemas ocorridos na sala de aula, entre os diferentes atores sociais e com outras questões de dentro e fora da própria escola, tomando consciência das mudanças sociais e educacionais.

Nesse sentido os Coordenadores Pedagógicos necessitam estar preparados, atualizados, dinâmicos e preocupados com a dinâmica e 
evolução dos estudantes, com as responsabilidades da instituição e com a comunidade escolar.

A Coordenação é uma função de assessoramento ao trabalho docente e para tanto, necessita de uma formação profissional que assegure o desenvolvimento da pessoa do educador enquanto cidadão e profissional e aos domínios dos conhecimentos (que é o objeto de trabalho com os estudantes), bem como para com os métodos pedagógicos que promovam e facilitem a aprendizagem.

A Formação Continuada, tanto de docentes quanto dos Professores Coordenadores Pedagógicos também assume particular importância, em decorrência do avanço científico e tecnológico e de exigência de um nível de conhecimentos sempre mais amplos e profundos na sociedade moderna. Ela é parte essencial da estratégia de melhoria permanente da qualidade da educação, e visará à abertura de novos horizontes na formação profissional. Portanto o Coordenador Pedagógico deve catalisar ações dentro das escolas, que permintam acompanhar os processos naturais de evolução social, desencadeados pelo avanço da ciência e da tecnologia.

Vemos assim, que a educação escolar não se reduz à sala de aula e se viabiliza pela ação articuladora entre todos os agentes educativos docentes, técnicos, funcionários administrativos e de apoio que atuam na instituição. Desta forma, na tabela 4 podem ser observados os resultados quando os Professores Coordenadores Pedagógicos foram questionados quanto às possíveis contribuições das reuniões de formação continuada promovidas pela mantenedora, a SEMED.

TABELA 4 - De que forma as reuniões de formação continuada promovidas pela SEMED contribuem com a tua prática diária?

\begin{tabular}{cc}
\hline Respostas & Percentual \\
\hline Contribui no esclarecimento e reflexão das funções & $80 \%$ \\
Contribuem na troca de informações e de experiências & $20 \%$ \\
\hline Total & $100 \%$ \\
\hline
\end{tabular}

Fonte: Dados da pesquisa. 
Os resultados demonstram que a grande maioria dos investigados manifestou que as reuniões contribuem para com os processos e reflexões sobre o desenvolvimento das funções inerentes ao cargo, e que $80 \%$ dos coordenadores salientaram essa percepção.

Segundo Nóvoa (1995, p. 26) "O diálogo entre os professores é fundamental para consolidar saberes emergentes da prática profissional". Essa troca entre os pares é fundamental para a efetivação da Proposta Pedagógica da escola, visto que a construção coletiva beneficia a todos e torna possível uma gestão mais democrática, na qual todos têm vez e voz. $\mathrm{Na}$ tabela 5, encontram-se os resultados, quando os Professores Coordenadores Pedagógicos foram questionados se as reuniões de formação continuada promovidas pela SEMED são relevantes.

TABELA 5 - Os temas abordados nas reuniões de formação continuada são relevantes? Qual outro assunto gostaria que fossem tratados na formação continuada da SEMED?

\begin{tabular}{lcc}
\hline & Respostas & Percentual \\
\hline Sim & & $80 \%$ \\
Não foi claro & $15 \%$ \\
Alguns sim & $5 \%$ \\
\hline \multicolumn{2}{c}{ Total } & $100 \%$ \\
\hline
\end{tabular}

Fonte: Dados da pesquisa.

A fala do Professor Coordenador Pedagógico F, traduz bem essa questão: "A interação com os demais colegas onde enfrentamos as mesmas dificuldades ou compartilhamos nossas experiências é muito gratificante e não nos sentimos sozinhos, sabemos que podemos contar com o apoio dos nossos coordenadores".

Os temas sugeridos para as reuniões podem ser observados a partir da Figura 4, efetuada pela técnica de nuvem de palavras: 
FIGURA 4 - Temas sugeridos pelos Coordenadores Pedagógicos para as reuniões de Formação Continuada promovida pela SEMED - Uruguaiana/RS.

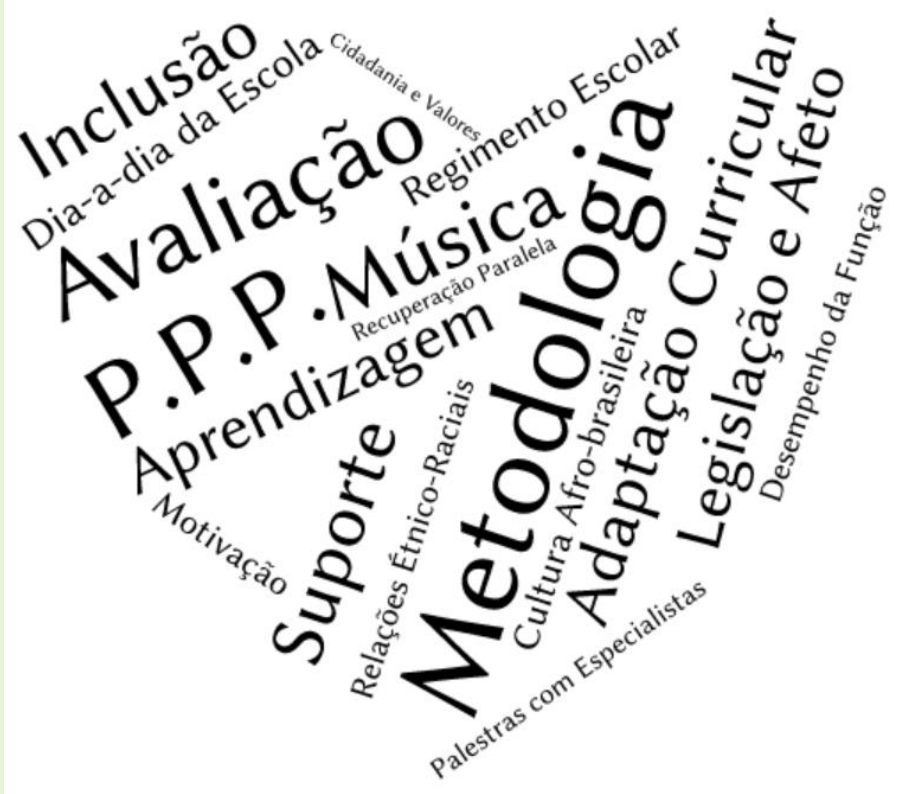

Fonte: Dados da pesquisa.

A partir dos resultados anteriores, é possível constatar que os Professores Coordenadores Pedagógicos reconhecem a importância da Formação Continuada promovida pela SEMED e demonstram anseio em estudar assuntos que ainda não estão claros, de modo a qualificar suas práticas nas escolas municipais.

Os investigados mencionaram a necessidade de estudar, principalmente, as questões metodológicas, avaliação, inclusão e adaptação curricular.

Os Coordenadores Pedagógicos também citam a importância de estudar mais os elementos que constituem o Projeto Político-Pedagógico das instituições escolares.

Os Coordenadores Pedagógicos reconhecem que esse espaço de formação continuada é fundamental, independente do espaço, sendo efetuado tanto pela mantenedora quanto pela própria escola.

Neste sentido, Vasconcellos (2006, p. 123) ressalta: 
Negar este espaço de trabalho na escola é contribuir para o desperdício da cultura pedagógica desenvolvida, para a mera justaposição de saberes (práticos e acadêmicos), e para o reforço da dicotomia teoria-prática, além de ser uma forma de negar o saber (e o poder) do professor. A troca de experiências e a partilha de saberes consolidam espaços de formação mútua, nos quais cada professor é chamado a desempenhar, simultaneamente, o papel de formador e de formando.

A ação da Coordenação Pedagógica pode então contribuir em muitos aspectos, não apenas com a formação continuada do professoreducador, mas na parceria com os gestores das escolas, no assessoramento e na articulação de programas e projetos educacionais.

Os Coordenadores Pedagógicos também realizaram uma autoavaliação, conforme mostra a tabela 6 abaixo:

TABELA 6 - Realiza uma autoavaliação de sua atuação como Professor Coordenador Pedagógico na Rede Municipal de Ensino?

\begin{tabular}{|c|c|}
\hline Respostas & Percentual \\
\hline $\begin{array}{l}\text { Tento desempenhar adequadamente na medida do possivel } \\
\text { Desenvolvo a função de forma adequada } \\
\text { Tenho limitações de conhecimento, contudo me esforço no } \\
\text { desenvolvimento da função. }\end{array}$ & $\begin{array}{l}55 \% \\
30 \% \\
15 \%\end{array}$ \\
\hline Total & $100 \%$ \\
\hline
\end{tabular}

Fonte: Dados da pesquisa.

Assim, foi possível constatar que, segundo os Professores Coordenadores Pedagógicos que atuam nas escolas municipais de Uruguaiana/RS, exercem suas funções da melhor maneira possível, independentemente de possuírem habilitação específica na área ou não. São profissionais que se esforçam para atuarem de maneira a atender as demandas existentes nas escolas.

Partindo das atribuições previstas em Lei Municipal e analisando as respostas obtidas através do questionário aplicado aos Coordenadores Pedagógicos, percebe-se que a visão que eles têm de suas funções dentro das unidades escolares ainda é limitada. 
As demandas da função dos Professores Coordenadores Pedagógicos são inúmeras. Além das questões de cunho burocrático, pode se enfatizar que a ação da Coordenação Pedagógica ocorre segundo já apontado por Vasconcellos (2006, p. 87), através da articulação do Projeto Político Pedagógico da escola, organizando a reflexão, a participação e dos meios para a concretização do mesmo. De tal forma que a escola possa cumprir sua tarefa de propiciar que todos os alunos aprendam e se desenvolvam como seres humanos plenos, partindo do pressuposto de que todos têm direito e são capazes de aprender.

\section{CONSIDERAÇÕES FINAIS}

Esta investigação traçou o perfil dos Professores Coordenadores Pedagógicos que atuam na Rede Municipal do município de Uruguaiana/RS, destacando as atribuições deste profissional, suas dificuldades e também as contribuições das reuniões promovidas pela SEMED em suas práticas.

O mundo em que vivemos vem apresentando mudanças e transformações em todos os âmbitos e as escolas vêm enfrentando desafios de todas as ordens: política, social, estrutural, etc. e isso reflete no trabalho desenvolvido em sala de aula e na atuação do Professor Coordenador Pedagógico.

Na realidade educacional contemporânea, há uma necessidade dos supervisores-educadores serem críticos e transformadores, diante das aceleradas mudanças sociais e das novas configurações sobre educação.

O trabalho do Coordenador Pedagógico é extremamente importante, mas também é um desafio, principalmente no que diz respeito à formação continuada do professor como uma das condições primordiais na melhoria do processo de ensino e aprendizagem.

Ao analisar as atribuições deste profissional, o percebemos como responsável pelo planejamento, organização e operacionalização do trabalho pedagógico desenvolvido pelos professores e isto é um desafio, bem como, construir a sua liderança com base nas relações saudáveis e nos princípios da ética profissional. 
Tendo em vista esse desafio, o papel do Coordenador Pedagógico revela-se fundamental, pois além de ser essa liderança técnico-pedagógica, é também um dos principais articuladores do PPP da escola em que atua. $\mathrm{Na}$ verdade, além de ser articulador do PPP da escola também é um mobilizador de toda a equipe escolar, vivenciando as suas atividades para a melhoria do fazer pedagógico da escola. Sua atuação deve ser voltada para o coletivo, promovendo reuniões para a formação continuada de seus educadores, sempre com vistas à qualificação e melhoria do processo de ensino e aprendizagem.

Dentre os desdobramentos de sua função, há necessidade do Coordenador Pedagógico interagir com o seu grupo harmoniosamente seja através de conversas, seja através de um acompanhamento efetivo, reuniões pedagógicas sistemáticas, apoio e auxílio para sanar as dificuldades do professor.

Nesta visão transformadora da Coordenação Pedagógica que todos desejamos, é aquela que integra os planos político e social, com vistas à melhoria do ensino e uma qualificação da aprendizagem. Percebeu-se então, que são vários os problemas enfrentados por estes profissionais, até mesmo porque muitos professores possuem a ideia de que os Professores Coordenadores Pedagógicos são "fiscais" da prática que estes realizam em suas salas de aula.

Desta forma, a ação dos Professores Coordenadores Pedagógicos se dá tanto no contato e mediação direta com o docente, quanto com a administração da escola e com a comunidade na qual a instituição está inserida, visto que a comunidade e o meio social é um dos fatores importantes que influenciam na aprendizagem dos alunos.

Em suma, a escola precisa adaptar-se às mudanças que ocorrem a todo tempo em nossa sociedade. E como o Professor Coordenador Pedagógico pode fazer isso de uma forma criativa, entusiástica, fundamentada e consciente de sua função social? Preparando os seus professores, motivando-os e fazendo com que se percebam parte de um todo responsável pela sua prática e pelo conjunto do trabalho desenvolvido. 
Então é este um dos principais desafios da ação destes profissionais: formar-se para poder formar, servir para poder liderar e agir para poder transformar.

\section{REFERÊNCIAS}

ALVES, N.; GARCIA, R. L. O fazer e o pensar dos Supervisores e Orientadores Educacionais. 4. ed. São Paulo: Edições Loyola, 1990.

BARDIN, L. Análise de Conteúdo. Lisboa: Edições 70, 1977.

BRASIL. Lei de Diretrizes e Bases da Educação Nacional. Lei n 9.394, de 20 de dezembro de 1996. Brasilia, 1996.

BRASIL. Plano Nacional de Educação 2014-2024. Brasília: Edições Câmara, 2014. Disponível em: <http://pne.mec.gov.br/images/pdf/pneconhecendo_20_metas.pdf>. Acesso em: 24 jun. 2016.

CULTURAL, L. Grande Dicionário Larousse Cultural da Língua Portuguesa. São Paulo: Nova Cultural, 1992.

FREIRE, P. Educação: o sonho possível. In: BRANDÃO, C. R. (Ed.). O Educador: vida e morte. Rio de Janeiro: Graal, 1982.

FREIRE, P. Pedagogia da indignação: cartas pedagógicas e outros escritos. São Paulo: UNESP, 2000.

MEDINA, A. S. Supervisor Escolar: parceiro político pedagógico do professor. In: SILVA JÚNIOR, C. A.; RANGEL, M. (Orgs.). Nove Olhares Sobre a Supervisão. 14. ed. Campinas: Papirus, 1997, p. 9 - 35.

NÓVOA, A. Vidas de Professores. Cidade do Porto: Porto Editora, 1995.

PLACCO, V. M. N. S.; ALMEIDA, L. R. O Coordenador Pedagógico e o Cotidiano da Escola. São Paulo: Edições Loyola, 2010.

RANGEL, M. Nove Olhares sobre a Supervisão. Campinas: Papirus, 1997.

SEVERINO, A. J. Metodologia do trabalho científico. 23 ed. São Paulo: Cortez, 2007.

SILVA, T. O que se esconde por trás de uma nuvem de palavras? 2013. Disponível em: <http://tarciziosilva.com.br/blog/ o-que-se-esconde-por-trasde-uma-nuvem-de-palavras/>. Acesso em: 10 jul. 2016. 
URUGUAIANA. Lei Municipal № 4.111/12. Estabelece o Plano de Carreira do Magistério Público Municipal de Uruguaiana que institui o respectivo Quadro de Cargos e Funções e dá outras providências. Uruguaiana, 2012.

VASCONCELLOS, C. S. Coordenação do trabalho pedagógico: do Projeto Político Pedagógico ao cotidiano da sala de aula. 7. ed. São Paulo: Libertad, 2006.

Recebido em: Outubro de 2017

Aprovado em: Junho de 2018 